\title{
Ontogeny of Endocrine Control of Osmoregulation in Chick Embryo
}

\section{Role of Pituitary Gland in Distribution of Water and lons among Embryonic and Extraembryonic Compartments}

\author{
Byron A. Doneen and Thomas E. SMith \\ Division of Biological Sciences, University of Michigan, Ann Arbor, Michigan 48109
}

Accepted October 16, 1981

\begin{abstract}
Distribution of water and of $\mathrm{Na}^{+}$and $\mathrm{Cl}^{-}$ions in blood and in allantoic, amniotic, and yolk sac fluids were observed during ontogeny of the chick embryo. A possible osmoregulatory role for pituitary hormones was inferred from differences in ionic concentrations and volumes of these compartments in partially decapitated (hypophysectomized) embryos and in intact and windowed-control embryos observed on Day 16.5 of incubation (20-21 days to hatching). $\mathrm{Na}^{+}-\mathrm{K}^{+}$-ATPase activity was also measured in both mesonephric and metanephric kidneys in control and in hypophysectomized and pituitary transplanted embryos. Some osmoregulatory defects in hypophysectomized embryos were reversed by transplantation of anterior and posterior lobes of the pituitary for 1 week beginning on Day 9 of incubation. Allantoic fluid volume was reduced and $\mathrm{Na}^{+}$and $\mathrm{Cl}^{-}$concentrations were elevated in this compartment in hypophysectomized embryos. Pituitary transplantation restored both measurements to control values. Amniotic fluid volume was not significantly changed by hypophysectomy when compared with windowed controls. Amniotic $\mathrm{Cl}^{-}$ concentration was also insensitive to hypophysectomy. Pituitary transplantation lowered amniotic fluid volume slightly, but elevated its $\mathrm{Cl}^{-}$concentration significantly. Hypophysectomy reduced the percentage water content in yolk sac and significantly increased hydration of the embryo. Pituitary transplantation partially restored fractional water content of yolk to control levels and reversed body hydration. Hypophysectomy and transplantation had no significant effects on serum $\mathrm{Na}^{+}$concentrations in the 16.5-day-old embryo. Activities of renal $\mathrm{Na}^{+}-\mathrm{K}^{+}$-ATPase were not significantly changed in mesonephros or metanephros by hypophysectomy or transplantation of one pituitary gland. Hormones of the pituitary gland appear to be required for normal distribution of water and ions in the chick embryo at 16.5 days of incubation. Possible target organs include both embryonic kidneys, but activities of renal $\mathrm{Na}^{+}-\mathrm{K}^{+}$-ATPase seem to be independent of pituitary hormones. Certain corrective actions obtained in response to metabolic hormones (thyroxine and corticosterone) suggest that some osmoregulatory defects observed in hypophysectomized embryos could result from impaired metabolism and a reduced rate of maturation rather than from the absence of specific osmoregulatory hormones of the pituitary gland.
\end{abstract}

The avian embryo is challenged during development with two opposing osmoregulatory problems, water loss and also excess water gain (Ar and Rahn, 1980). Despite adaptations in nest design and in brooding behavior of parents, water loss in the terrestrial environment occurs because the porous egg shell is necessarily open for exchange of respiratory gases. Most bird eggs lose about $15 \%$ of their initial weight as water vapor during incubation. Losses greater than $15 \%$ produce significant mor- tality (Ar and Rahn, 1980). Avian embryos are also at risk with respect to excess hydration. Early in incubation, water is derived principally from yolk albumen (Simkiss, 1980). Later in incubation, hydration is a potential consequence of the utilization of yolk lipid as the principle energy reserve, oxidation of fat being accompanied by the production of metabolic water (Ar and Rahn, 1980). Thus, developing embryos need to balance water loss with gain. This consideration alone suggests the need for 
adaptive mechanisms to regulate content and distribution of water among various compartments of the egg. Hoyt (1979) observed that the chick in ovo can protect against excessive water loss by shifting fluid from the allantois to embryo.

The possible role of pituitary gland in regulation of hydromineral balance in the chick embryo is the concern of this paper. The emphasis is on changes observed in the volumes of extraembryonic compartments and on their $\mathrm{Na}^{+}$and $\mathrm{Cl}^{-}$concentrations following partial decapitation and pituitary transplantation. In some experiments, the effects of hypophysectomy and transplantation on kidney $\mathrm{Na}^{+}-\mathrm{K}^{+}$-ATPase were also observed. This transport enzyme is required, at least indirectly, for the renal resorption of $\mathrm{Na}^{+}$(Perez-Gonzalez de la Manna et al., 1980), and is thus coupled to the production of dilute allantoic fluid. In most vertebrate kidneys, $\mathrm{Na}^{+}-\mathrm{K}^{+}$-ATPase activity is under multihormonal control (Berl and Betler, 1979; Holmes and Pearce, 1979). Maturational and regulatory roles of hormones in the developing kidney of the bird are of special interest because the avian embryo possesses, from the midpoint of incubation through 2 weeks after hatching, two functional types of kidneys, the transitional mesonephros, and also the metanephros which persists into adulthood (Romanoff, 1960). As no information is available on the endocrine regulation of renal function in the embryo, we measured $\mathrm{Na}^{+}-\mathrm{K}^{+}$-ATPase in both kidneys separately. The companion paper (Doneen and Smith, 1982) reports effects of specific pituitary hormones, prolactin and arginine vasopressin, and also of aldosterone, on volumes and ion concentrations of embryonic and extraembryonic compartments and on renal (mesonephros and metanephros) $\mathrm{Na}^{+}-\mathrm{K}^{+}$-ATPase activity. A few brief reports have implicated pituitary hormones, including prolactin, as possible osmoregulatory agents (Thommes and Lamping, 1966; Lamping and Thommes, 1967; Murphy et al., 1980). A preliminary account of some of the results in this paper appeared in abstract form (Doneen and Smith, 1980).

\section{MATERIALS AND METHODS}

Embryos. Fertilized eggs (Rhode Island Red $\times$ White Leghorn obtained from Dave's Eggs and Poultry, Ann Arbor) were incubated in a forced-draft stationary incubator at $38.7^{\circ}$, humidity, $80 \%$. Four groups of embryos were studied: (1) intact embryos; (2) windowed-control embryos obtained by making the same small hole in the egg shell as required to decapitate embryos and sealing with adhesive tape; (3) hypophysectomized embryos (partially decapitated at $36-40 \mathrm{hr}$ of incubation according to Fugo (1940); and (4) hypophysectomized embryos which received a single pituitary graft on 9.5 days of incubation. Pituitary transplants were obtained from 2-day-old posthatch donor chicks. Pituitary transplants included both anterior and posterior lobes and were placed in a small lesion made near an artery on the chorioallantoic membrane (Betz, 1967). Viability of tissue could be judged on 16.5 days of incubation by vascularization of the transplant. The transplanted group includes only those embryos meeting this criterion for successful transplantation. In two experiments, small pieces of brain were used as transplantation controls. These control transplants failed to become vascularized. Results from these groups were pooled with hypophysectomized embryo from which they did not differ ( $t$ test). In most experiments, measurements made on samples collected from windowed-controls differed somewhat from intact controls. Windowedcontrol embryos may have suffered additional stress, possibly osmoregulatory in nature, since the window, even when taped, enlarged the effective pore area of eggs considerably.

Collection of fluid and tissue samples. Eggs were placed on ice for $5 \mathrm{~min}$ to minimize bleeding during sample collection (Hoyt, 1979). In intact eggs a hole was made in the shell in the region of the air space; in all others eggs, samples were collected through the window made previously. A 5 -ml syringe with a $22-$ gauge needle was used to withdraw first the allantoic fluid and then the amniotic fluid. Fluid volumes were recorded to the nearest $0.1 \mathrm{ml}$ and samples were stored at $4^{\circ}$. After fluids were withdrawn, a chorioallantoic artery was punctured and a blood sample collected in an ammonium-heparinized microhematocrit tube. The embryo was then separated from the yolk sac. The mesonephros and metanephros were dissected separately and immediately frozen $\left(-20^{\circ}\right)$. To determine free water content, wet weight-dry weight measurements $\left(60^{\circ} \times 6\right.$ days) were made separately on the embryo and the yolk sac. Water contents of the embryo and yolk sac were expressed as grams water (the 
difference between wet and dry weights) and also as percentage wet weight. Preliminary experiments showed that acute exposure to cold did not alter plasma $\mathrm{Na}^{+}$concentration or allantoic fluid $\mathrm{Na}^{+}$and $\mathrm{Cl}^{-}$concentrations in the 16.5-day embryos compared with noncooled eggs. This finding was crucial in validating the method of sample collection since other investigators have shown that the embryo responds to stress at this time by releasing corticosterone (Wise and Frye, 1973) and thyroid hormone (Thommes et al., 1979), hormones which might acutely influence osmoregulatory performance.

Ion concentration. Allantoic and amniotic fluids and blood were centrifuged to remove cellular components and solids (such as uric acid in the allantoic fluid). $\mathrm{Na}^{+}$ concentrations were measured using atomic absorption spectrophotometry (Perkin-Elmer Model 290B) with $\mathrm{NaCl}$ as a standard. Chloride concentrations were measured using coulometric titration (Buchler chloridometer).

Kidney $\mathrm{Na}^{+}-\mathrm{K}^{+}$-ATPase activity. A slightly modified version of the $\mathrm{Na}^{+}-\mathrm{K}^{1}$-ATPase enzyme assay procedure of Post and Sen (1967) was used to measure enzyme activity in mesonephros and metanephros. Tissues were homogenized in a $0.01-M$ imidazole buffer containing $0.25 M$ sucrose, $17.0 \mathrm{mM} \mathrm{NaCl}, 5.5$ $\mathrm{mM} \mathrm{Na} \mathrm{Na}_{2}$ EDA, and $4.9 \mathrm{mM} \mathrm{MgCl}_{2}, \mathrm{pH}$ 7.4. Protein $(50-150 \mu \mathrm{g})$ was assayed in a solution containing 0.1 $M$ imidazole, $150.0 \mathrm{mM} \mathrm{NaCl}, 30 \mathrm{mM} \mathrm{KCl}, 7.5 \mathrm{mM}$ $\mathrm{MgCl}_{2}$, and $5.0 \mathrm{mM} \mathrm{Na}$ ATP, pH 7.4. Preliminary experiments established that these $\mathrm{Na}^{+}$and $\mathrm{K}^{+}$concentrations produced maximum enzyme activity. Ouabain (G-strophanthin, Sigma; $0.5 \mathrm{mM}$ ) was used to specifically inhibit $\mathrm{Na}^{+}-\mathrm{K}^{+}$-dependent activity in duplicate assay tubes. After incubation for $40 \mathrm{~min}$ at $39^{\circ}$, the reaction was stopped by addition of $1.0 \mathrm{ml}$ cold $10 \%$ trichloroacetic acid and tubes were transferred to an ice bath. A 0.5-ml aliquot was used for determination of phosphorus by the method of Peterson (1978), except that $2 \%$ Elon ( $p$-methylaminophenol sulfate; Eastman) in 5\% sodium sulfite was used as reducing agent (LeBel et al., 1978). $\mathrm{Na}^{+}-\mathrm{K}^{+}$-ATPase activity ( $\mu$ mol $P_{\mathrm{I}} \mathrm{mg}^{-1}$ protein $\mathrm{hr}{ }^{1}$ ) was calculated as the ouabain-sensitive ATP-hydrolyzing activity (Post and Sen, 1967). Protein determinations were made using the coomassie blue reaction (Bio-Rad) with $\gamma$-globulin as standard.

Hormone treatment. In one experiment, thyroxine $\left(\mathrm{T}_{4}\right)$ and corticosterone acetate were administered to hypophysectomized embryos. Fifty microliters of $0.9 \%$ sterile saline containing $150 \mathrm{ng} \mathrm{T}_{4}, 5 \mu \mathrm{g}$ corticosterone acelate and $2 \%$ ethanol were applied to a well-vascularized region of the chorioallantoic membrane on Days 11, 13, and 15 of incubation. Control injections consisted of $0.9 \%$ saline $-2 \%$ ethanol. Samples were collected on Day 16.5 and analyzed as described.

Statistics. Most experiments involved multiple comparisons. Data were first subjected to one-way analysis of variance (ANOV). Upon rejection of the null hypothesis, data were then analyzed by Dunnett's test for comparison of a control mean with each other group mean (Steel and Torrie, 1980). Windowed embryos were selected as the control group. In some experiments, involving a single variable and two groups, the Student's $t$ test (two-sided) was employed. When experimental and controls showed unequal variances, the adjusted $t$ test was used (Steel and Torrie, 1980).

\section{RESULTS}

The first experiment examined the time course of pituitary-dependent maturation of osmoregulatory function in the chick embryo. Measurements of the volume and $\mathrm{Cl}^{-}$ concentration of allantoic fluid were selected as key indicators of osmoregulatory function since allantoic fluid composition reflects the summed output of three major osmoregulatory tissues, kidneys, gut, and chorioallantoic membrane. Allantoic fluid $\mathrm{Cl}^{-}$concentration decreased progressively after 10 days of incubation (Fig. 1) and reached its minimum value on Day 18 (hatching $=20-21$ days). In hypophysectomized embryos, allantoic fluid $\mathrm{Cl}^{-}$concentrations were elevated on all days compared with intact embryos (Fig. 1). Hypophysectomized embryos were not examined at 18 days because of the large mortality occurring at or just prior to this time in incubation.

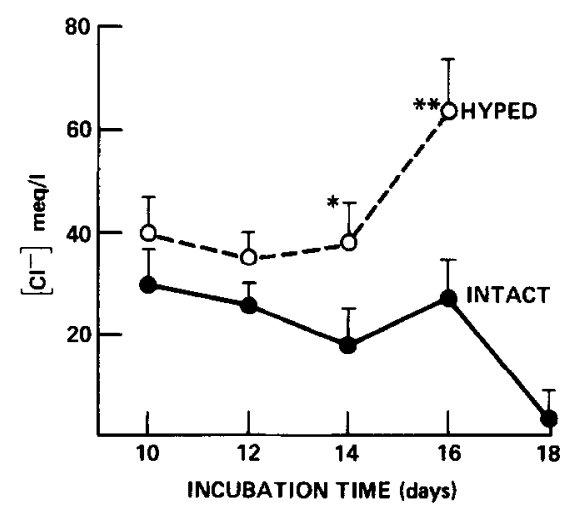

FIG. 1. Allantoic fluid $\mathrm{Cl}^{-}$concentration in intact and hypophysectomized (hyped) embryos during incubation. Values shown are means \pm SE of 4 to 5 measurements and were significantly different on Days 14 and $16 .{ }^{*} P \leqslant 0.05 ;{ }^{* *} P \leq 0.01(t$-test $)$. 
Allantoic fluid $\mathrm{Cl}^{-}$concentration was also observed in windowed-control embryos on Days 14,16 , and 18. $\mathrm{Mean}^{-}$concentration in this group paralleled that of intact embryos, but was slightly elevated on Days 16 and 18 above the unoperated group (by 5 and $12 \mathrm{meq} / \mathrm{liter}$, respectively). The biggest difference in allantoic fluid between intact and windowed-control embryos, on the one hand, and the hypophysectomized group on the other was observed on Day 16. Accordingly, the remaining experiments focused on effects of pituitary ablation and transplantation at this time.

The effects of hypophysectomy and pituitary transplantation on volume of allantoic fluid and on its $\mathrm{Na}^{+}$and $\mathrm{Cl}^{-}$concentrations are summarized in Figs. 2 and 3. Allantoic fluid volume was significantly depressed $(P$ $\leqslant 0.01$ ) by hypophysectomy when compared with windowed-control embryos (Fig. 2). Pituitary transplantation for 1 week (Days 9.5-16.5) partially restored allantoic fluid volume to the windowed-control level $(P \leqslant 0.05)$. As observed above, the mean volume of allantoic fluid in windowedcontrol embryos differed significantly from that observed in intact embryos. This difference (and others to be noted) may be

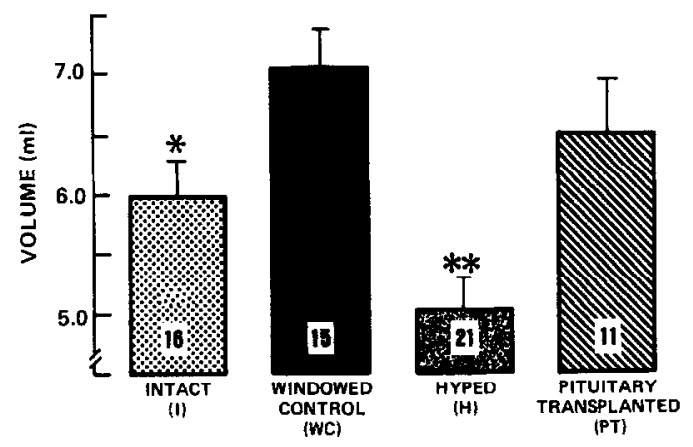

Fig. 2. Volume of allantoic fluid in intact (I), windowed-control (WC), hypophysectomized $(\mathrm{H})$, and pituitary-transplanted (PT; 1 week) embryos on Day 16.5 of incubation. Bars are means and vertical lines are SE. Number of embryos shown in parentheses. $F$ $=3.86 ; P \leqslant 0.05$ (ANOV); ${ }^{*} P<0.05,{ }^{*} P<0.01$ (Dunnett's test; WC, control).
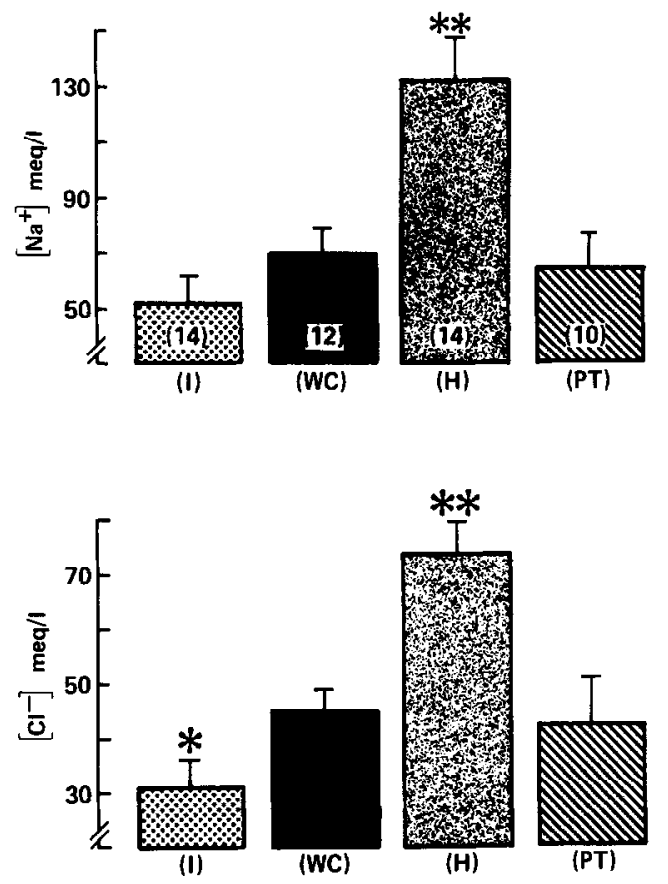

FIG. 3. Sodium and chloride concentration in allantoic fluid of intact (I), windowed-control (WC), hypophysectomized $(\mathrm{H})$, and pituitary-transplanted (PT) 16.5-day-old embryos. Values are means $\pm \mathrm{SE}$; number of embryos shown in parentheses. Upper: Allantoic fluid $\mathrm{Na}^{+}$; lower: allantoic fluid $\mathrm{Cl}^{-}$. For $\mathrm{Na}^{+}: F$ $=8.75, P \leqslant 0.01 ; * * P \leqslant 0.01$ (Dunnett's test; WC, control). For $\mathrm{Cl}^{-}: F=5.55, P \leqslant 0.01 ;{ }^{* *} P \leqslant 0.01$ (Dunnett's test; WC, control).

attributed to stress-related factors, possibly mediated by hormones. Hypophysectomy significantly elevated allantoic fluid $\mathrm{Na}^{+}$ and $\mathrm{Cl}^{-}$concentrations above the levels observed in intact and windowed-control embryos $(P \leqslant 0.01)$ (Fig. 3). The ameliorative action of pituitary transplantation can be clearly seen from the lowered ion concentrations obtained in this group.

In Table 1 volume of amniotic fluid and its $\mathrm{Cl}^{-}$concentration in response to hypophysectomy and to pituitary transplantation are summarized. The volume of this compartment was highly variable and appeared not to depend on the pituitary gland. $\mathrm{Cl}^{-}$concentration in amniotic fluid was also not altered by hypophysectomy, but pituitary transplantation increased am- 
TABLE 1

AMNiotic Fluid Volume AND $\mathrm{Cl}^{-}$Concentration in INTACT, CONTROL, HYPOPHYSECTOMIZED, AND Pituitary Transplanted Embryos AT 16.5 DAYS OF INCUBATION

\begin{tabular}{lrcc}
\hline & $n$ & $\begin{array}{c}\text { Volume (m) } \\
\text { (mean } \pm \mathrm{SE})\end{array}$ & $\begin{array}{c}\mathrm{Cl}^{-} \text {(meq/liter) } \\
\text { (mean } \pm \mathrm{SE})\end{array}$ \\
\hline Intact & 8 & $1.9 \pm 0.6$ & $100 \pm 4$ \\
Windowed control & 12 & $2.1 \pm 0.5$ & $96 \pm 9$ \\
Hypophysectomized & 17 & $2.8 \pm 0.6$ & $95 \pm 10$ \\
$\begin{array}{l}\text { Pituitary } \\
\quad \text { transplanted }\end{array}$ & 11 & $1.3 \pm 0.4$ & $122 \pm 6^{*}$ \\
\hline
\end{tabular}

Note, Volume: $F=2.28$; NS (not significantly different from windowed-controls, ANOV); $\mathrm{Cl}^{-}: F=3.14 ; P \leqslant 0.05$ (ANOV).

$* \boldsymbol{P} \leqslant 0.05$ (Dunnett's test).

niotic $\mathrm{Cl}^{-}$above the windowed-control $(P$ $\leqslant 0.05$ ) and hypophysectomized values (Table 1).

Plasma $\mathrm{Na}^{+}$concentration in the 16.5 day-old embryo in the four experimental groups is shown in Table 2. Blood $\mathrm{Na}^{+}$was maintained at a generally uniform value, around $170 \mathrm{meq} / \mathrm{liter}$, in embryos subjected to windowing or to removal or replacement of the pituitary. In all operated groups, however, plasma $\mathrm{Na}^{+}$was slightly higher than in intact embryos.

Effects of hypophysectomy and transplantation on total and percentage water contents of the yolk are shown in Figure 4. The total free water (difference between wet and dry weights) in yolk was slightly, though insignificantly, elevated in hypophysectomized embryos and in those receiving pituitary transplants compared with

TABLE 2

Plasma Na ${ }^{+}$Concentration in the Four Groups OF EMBRYOS ON DAY 16.5 OF INCUBATION

\begin{tabular}{lrc}
\hline & $n$ & $\begin{array}{c}\text { Mean } \pm \text { SE } \\
\text { (meq/liter) }\end{array}$ \\
\hline Intact & 9 & $139 \pm 9$ \\
Windowed control & 9 & $166 \pm 20$ \\
$\begin{array}{l}\text { Hypophysectomized } \\
\begin{array}{l}\text { Pituitary } \\
\text { transplanted }\end{array}\end{array}$ & 12 & $172 \pm 12$ \\
\hline
\end{tabular}

Note, $F=2.12$; NS (ANOV).

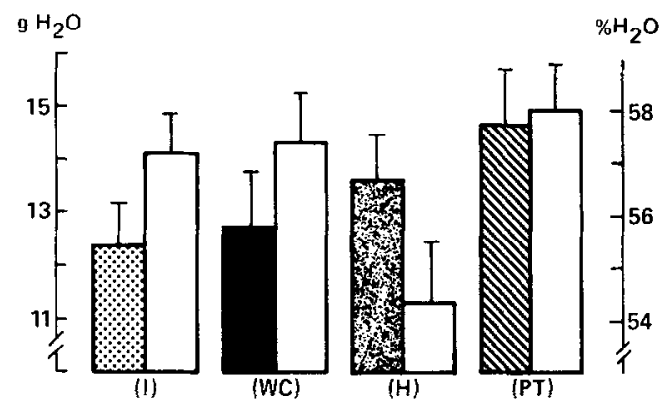

FIG. 4. Free water content (filled bars) and percentage water content (white bars) of yolk in 16.5-day-old embryos. Free water content $=$ wet weight - dry weight. Percentage water content: ratio of free water content divided by total wet weight $(\times 100)$. Values shown are means \pm SE. $n$ for each group: Intact (I), 14; windowed control (WC), 12; hypophysectomized (H), 18; pituitary transplanted (PT), 10. For free water: $F=2.67$, NS (ANOV). For water (\%): $F=1.54$, NS (ANOV).

windowed controls. The mean percentage water content was reduced from $57.5 \%$ in windowed controls to $54.7 \%$ in hypophysectomized embryos, but this difference was not significant. The total weight of yolk in the pituitary-transplanted group was nearly identical to that in hypophysectomized embryos (hypophysectomized mean wet weight, $25.4 \mathrm{~g}$; transplanted, $25.3 \mathrm{~g}$ ), but transplantation restored percentage water content to a value in excess of the hypophysectomized level (Fig. 4).

Total free and percentage body water content in controls and operated groups of embryos are presented in Fig. 5. Total body water in each group was proportional to body weight. Intact 16.5-day-old embryos displayed the largest total weight followed in descending order by windowed-controls, hypophysectomized and pituitary-transplanted embryos. Hypophysectomy significantly $(P<0.01)$ elevated the percentage whole-body water content. Pituitarytransplantation significantly reduced the excess hydration observed in hypophysectomized embryos.

$\mathrm{Na}^{+}-\mathrm{K}^{+}$-ATPase activities were assayed separately in mesonephros and metanephros in the four experimental groups on Day 


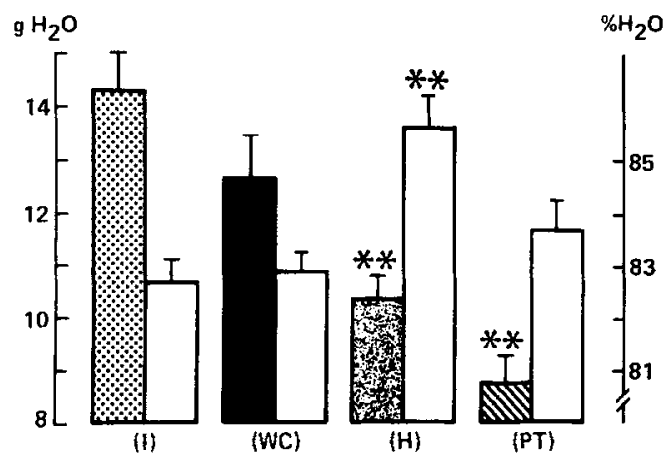

FIG. 5. Free water content and percentage water content of 16.5-day-old embryos. Values presented and $n$ as in Fig. 4. For free water: $F=26.16, P<0.01$ (ANOV). For water (\%): $F=29.33, P \leqslant 0.01$ (ANOV). ${ }^{* *} P \leqslant 0.01$ (Dunnett's test; WC control).

16.5 of incubation. These data are presented in Table 3. In mesonephros, hypophysectomy depressed enzyme activity, but the reduction was not statistically significant. Embryos which received a pituitary transplant for 1 week displayed modestly increased mesonephric $\mathrm{Na}^{+}-\mathrm{K}^{+}$-ATPase when compared with the hypophysectomized group. In all groups, $\mathrm{Na}^{+}-\mathrm{K}^{+}$ ATPase activity was uniformly less in metanephros than in mesonephros (Table $3)$. Activity of the enzyme in metanephros did not differ in hypophysectomized embryos when compared with intact or windowed-controls. Pituitary transplantation also failed to effect $\mathrm{Na}^{+}-\mathrm{K}^{+}$-ATPase activity in metanephros.

TABLE 3

ACtivities of $\mathrm{NA}^{+}-\mathrm{K}^{+}$-ATPASE IN MESONEPHROS AND METANEPHROS IN FOUR GROUPS OF EMBRYoS AT 16.5 DAYS OF INCUBATION

$\mathrm{Na}^{+}-\mathrm{K}^{+}$-ATPase

$\left(\mu \mathrm{mol} P_{\mathrm{t}} \mathrm{mg}^{-1} \mathrm{hr}^{-1}\right)($ mean $\pm \mathrm{SE})$

\begin{tabular}{|c|c|c|c|c|}
\hline & \multicolumn{4}{|c|}{$\begin{array}{c}\mathrm{Na}^{+}-\mathrm{K}^{+}-\mathrm{ATPase} \\
\left(\mu \mathrm{mol} P_{\mathrm{f}} \mathrm{mg}^{-1} \mathrm{hr}^{-1}\right)(\text { mean } \pm \mathrm{SE})\end{array}$} \\
\hline & $n$ & Mesonephros & $n$ & Metanephros \\
\hline Intact & 11 & $3.90 \pm 0.39$ & 14 & $2.69 \pm 0.13$ \\
\hline Windowed control & 11 & $4.20 \pm 0.48$ & 11 & $2.62 \pm 0.19$ \\
\hline Hypophysectomized & 11 & $3.43 \pm 0.33$ & 12 & $2.63 \pm 0.36$ \\
\hline $\begin{array}{l}\text { Pituitary } \\
\text { transplanted }\end{array}$ & 10 & $4.94 \pm 0.78$ & 10 & $3.17 \pm 0.32$ \\
\hline
\end{tabular}

Note. Mesonephros, $F=1.48$; metanephros, $F=1.06$. Both measurements showed no significant differences (ANOV).
Table 4 summarizes some effects of three injections of thyroxine (150 $\mathrm{ng} /$ day) and corticosterone acetate $(5 \mu \mathrm{g})$ administered in combination to hypophysectomized embryos on Days 11, 13, and 15 of incubation with embryos sampled on Day 16.5. Hormone treatment significantly elevated allantoic fluid volume and also reduced its $\mathrm{Cl}^{-}$concentration ( $t$ test; $P \leqslant 0.01$ ). There was also a small reduction in the mean amniotic fluid volume in the hormone-treated group, but this highly variable measure was not significantly different in the two groups. With respect to renal $\mathrm{Na}^{+}-\mathrm{K}^{+}$-ATPase activity, $\mathrm{T}_{4}$ and corticosterone acetate increased mesonephric enzyme activity $(P \leqslant$ 0.05 ), but did not alter activity of the transport enzyme in the metanephros.

\section{DISCUSSION}

Several osmoregulatory defects have been observed in the 16.5-day-old chick embryo deprived of its pituitary gland by partial decapitation. Some defects were corrected by transplantation of a single pituitary gland (anterior and posterior lobes) for 1 week. These results, obtained using the classical endocrine strategy of gland ablation and replacement, suggest an osmoregulatory role for pituitary hormones during ontogeny of the avian embryo. As discussed below, however, hypophysectomized embryos can also show deficits which are ostensibly osmoregulatory in nature, but which may actually be secondary consequences of impaired metabolism or reduced rates of growth and organogenesis (Betz, 1975). One objective of this work was to learn whether compromised osmoregulation could be distinguished from the more generalized defects occurring in the hypophysectomized embryo.

Hypophysectomy altered the volume and monovalent ion concentrations in the major extraembryonic compartments in the egg at 16.5 days of incubation. Allantoic fluid 
TABLE 4

Effects of Thy roxine and Corticosterone acetate Treatment on Volume and CL- Concentration of SOME EXTRAEMBryonic COMPARTMENTS AND ON ACTIVITIES OF KIDNEY NA ${ }^{+}-\mathrm{K}^{+}$-ATPASE IN 16.5-DAY-OLD HYPOPHYSECTOMIZED EMBRYOS

\begin{tabular}{|c|c|c|c|c|}
\hline & $n:$ & $\begin{array}{c}\text { Control } \\
(0.9 \% \text { saline } \times 3 \text { days }) \\
7\end{array}$ & $\begin{array}{c}\text { Hormone Treated } \\
\left(\mathrm{T}_{4}(150 \mathrm{ng})+\text { corticosterone }\right. \\
\text { acetate }(5 \mu \mathrm{g}) \times 3 \text { days }) \\
6\end{array}$ & $P$ \\
\hline $\begin{array}{l}\text { Allantoic fluid volume } \\
(\mathrm{ml})\end{array}$ & & $4.1 \pm 0.4^{*}$ & $7.4 \pm 0.9$ & $<0.01$ \\
\hline $\begin{array}{l}\text { Allantoic fluid }\left[\mathrm{Cl}^{-}\right] \\
\text {(meq/liter) }\end{array}$ & & $68.7 \pm 4.0$ & $52.0 \pm 3.9$ & $<0.01$ \\
\hline $\begin{array}{l}\text { Amniotic fluid volume } \\
(\mathrm{ml})\end{array}$ & & $2.2 \pm 0.9$ & $1.3 \pm 0.7$ & NS \\
\hline $\begin{array}{l}\text { Mesonephric } \mathrm{Na}^{+}-\mathrm{K}^{+} \text {-ATPase } \\
\left(\mu \mathrm{mol} \boldsymbol{P}_{\mathrm{i}} \mathrm{mg}^{-1} \mathrm{hr}^{-1}\right)\end{array}$ & & $3.21 \pm 0.56$ & $4.57 \pm 0.42$ & $<0.05$ \\
\hline $\begin{array}{l}\text { Metanephric } \mathrm{Na}^{+}-\mathrm{K}^{+} \text {-ATPase } \\
\quad\left(\mu \mathrm{mol} P_{1} \mathrm{mg}^{-1} \mathrm{hr}^{-1}\right)\end{array}$ & & $2.53 \pm 0.17$ & $2.79 \pm 0.33$ & NS \\
\hline
\end{tabular}

Note. Treatment schedule: Hormones or $0.9 \%$ saline $-2 \%$ ethanol were administered on Days 11,13 , and 15 of incubation. Samples collected on Day 16.5. The $t$ test (two-sided) was used to compare hormone treated with control. NS, not significantly different at $P \leqslant 0.05$. Values are mean $\pm \mathrm{SE}$.

contents reflect activities of several osmoregulatory tissues, including kidneys, gut, and chorioallantoic membrane. These epithelia and other tissues are thus potential target organs for pituitary hormones. Allantoic fluid volume in the hypophysectomized group was significantly depressed compared with windowed controls (Fig. 2). Allantoic fluid $\mathrm{Na}^{+}$and $\mathrm{Cl}^{-}$concentrations were also elevated following hypophysectomy (Fig. 3) as first shown by Lamping and Thommes (1967). Allantoic fluid volume (Fig. 2), and $\mathrm{Na}^{+}$and $\mathrm{Cl}^{-}$concentrations, were restored or partially restored to control values by pituitary transplantation. These results indicate that the normal production of dilute allantoic fluid requires pituitary hormones, but do not identify specific hormones or target organs. Actions of pituitary hormones on embryonic kidneys are noted below and in the companion paper (Doneen and Smith, 1982).

Responses of amniotic fluid volume to various treatments were variable, and no clear pituitary dependence was demonstrated (Table 1). Hypophysectomy slightly elevated amniotic fluid volume above that observed in windowed controls. Since hypophysectomized embryos were considerably smaller than control embryos, the increased amniotic volume observed after hypophysectomy was extreme when allowance for differences in body size is made. However, $\mathrm{Cl}^{-}$concentration in amniotic fluid was maintained at control levels even in absence of the pituitary (Table 1). Pituitary transplantation decreased the mean volume of amniotic fluid compared with the hypophysectomized value; but the embryos receiving transplants were the smallest observed and this may account for the reduction in volume of the amniotic compartment. Transplantation also elevated $\mathrm{Cl}^{-}$ concentration about $25 \mathrm{meq} / \mathrm{liter}$ above intact and windowed-control values (Table 1).

Serum $\mathrm{Na}^{+}$was not markedly different among treatment groups, which suggests that $\mathrm{Na}^{+}$can be regulated at this time in incubation independently of pituitary hormones. The lack of effect of hypophysectomy on blood $\mathrm{Na}^{+}$at 16.5 days can be distinguished from the effect of pituitary ablation in 12-day-old embryos. Murphy et al. (1980) have shown that hypophysectomy 
elevated serum $\mathrm{Na}^{+}$at the earlier time. Thus, in some measures of osmoregulatory performance, sensitivity to hypophysectomy varies in a time-dependent fashion. Differences in osmoregulatory responses to pituitary prolactin in embryos treated with this hormone early and late in incubation are discussed in the following paper.

Minor changes in the water content of yolk were produced by hypophysectomy (Fig. 4). The tendency toward reduced percentage water content in this compartment in decapitated embryos was reversed by pituitary transplantation but these differences were not statistically significant. Differences in hydration of yolk may have been indirect consequences of differences in metabolic rate in the experimental groups (Betz, 1975). The weight of the solid components in yolk (principally protein and fat) was also increased following hypophysectomy (calculated from Fig. 4; cf. Doneen 1981). Increased lipid and protein in yolk of hypophysectomized embryos is consistent with impaired metabolism, and reduced mobilization of stored nutrients due, in part, to absence of pituitary TSH and ACTH (Betz, 1967). Therefore, some defects in distribution of water in hypophysectomized embryos and the ameliorative actions of pituitary transplantation might have been coupled to disturbed and partially repaired metabolism, respectively. Mobilization of water from albumen and from hydrolysis of yolk lipids will be decreased in proportion to the reduction in metabolic rate (Ar and Rahn, 1980; Simkiss, 1980). Reduced allantoic fluid volume observed in hypophysectomized embryos would be expected, therefore, even with normal osmoregulatory mechanisms, simply because less water is made available to the embryo. Hypophysectomized embryos were also considerably smaller than controls (Betz, 1967) and, therefore, have a reduced requirement or renal capacity for production of allantoic fluid. These considerations illustrate a possible limitation of the hypophysectomized embryo as a model for understanding actions of specific pituitary osmoregulatory hormones. In hypophysectomized embryos metabolic defects necessarily occur in parallel with osmoregulatory ones, and the metabolic deficits by themselves can interfere with mobilization and distribution of water and ions.

At first observed by Fugo (1940), hypophysectomized embryos become hydrated (Fig. 5). In hypophysectomized and transplanted embryos, total body water was lower than in windowed and intact controls (Fig. 5) because body size was sharply reduced in the operated embryos. Pituitary transplantation for 1 week did not restore normal growth as judged by body weight. Indeed, pituitary-transplanted embryos were slightly smaller on the average than hypophysectomized ones. However, transplantation of one pituitary did reduce the hydration seen in hypophysectomized embryos (Fig. 5). This result is similar to that of Thommes and McCarter (1966) who observed approximately normal hydration in hypophysectomized embryos receiving pituitary transplants obtained from chick embryos at 10 days of incubation.

Among possible target organs for osmoregulatory pituitary hormones are the two kidneys of the avian embryo, the mesonephros and metanephros. Activity of $\mathrm{Na}^{+}-\mathrm{K}^{+}-\mathrm{ATPase}$ can be used as one indirect index of $\mathrm{Na}^{+}$reabsorption by kidney tubules (Perez-Gonzalez de la Manna et al., 1979), though it is not possible to extrapolate rates of $\mathrm{Na}^{+}$reabsorption directly from enzyme activity. The kidneys are major, though not exclusive, sources of allantoic fluid and it seemed reasonable that $\mathrm{Na}^{+}$$\mathrm{K}^{+}$ATPase activity might vary inversely with allantoic fluid $\mathrm{Na}^{+}$and $\mathrm{Cl}^{-}$concentration. Activities of $\mathrm{Na}^{+}-\mathrm{K}^{+}$-ATPase in mesonephros and metanephros, however, were similar in all groups (Table 3).

Data in Table 4 indicate that some osmoregulatory defects in hypophysectomized embryos can be eliminated by 
treatment with $T_{4}$ and corticosterone, hormones known to be controlled by pituitary TSH and ACTH, and which are secreted on or prior to Day 16 of incubation in the chick embryo (Thommes and Hylka, 1977; Kallicharan and Hall, 1977; Wise and Frye, 1973). These hormones given in combination can mimic some actions of pituitary transplantation by producing increased allantoic fluid volume and decreased $\mathrm{Cl}^{-}$ concentration in this compartment (Table 4). Treatment with the metabolic hormones also elevated $\mathrm{Na}^{+}-\mathrm{K}^{+}$-ATPase activity in mesonephros (Table 4). The response in mesonephros was greater than that obtained by pituitary transplantation (Table 3 ).

Despite pitfalls, the hypophysectomized chick embryo has been a useful experimental system for endocrinological developmental studies (Betz, 1975) and, with some amphibians, belongs to a small group of vertebrate embryos in which the pituitary can be eliminated and replaced in the classical manner. The hypophysectomized chick embryo can also be of use in studying osmoregulatory hormones during development if its limitations are recognized and dealt with by design of proper experimental controls. The results obtained with $T_{4}$ and corticosterone (Table 4) emphasize anew that no hormone acts in isolation. The metabolic hormones can also be considered as osmoregulatory ones in the sense that one or both seem to be required for function of osmoregulatory structures such as the embryonic kidney, though other hormones may actually control transport rate or tubular permeability. Finally, in the avian embryo, corticosterone may be an osmoregulatory hormone in the usual sense. In the adult bird this steroid promotes $\mathrm{K}^{+}$ secretion and $\mathrm{Na}^{+}$absorption by kidney and salt secretion by nasal gland (Holmes and Pearce, 1979).

In summary, the hypophysectomized chick embryo showed many abnormalities in the distribution of water and ions, especially among extraembryonic compart- ments. These embryos also showed altered renal function, as inferred from increased volume and $\mathrm{Na}^{+}$and $\mathrm{Cl}^{-}$concentration in allantoic fluid and from slightly depressed $\mathrm{Na}^{+}-\mathrm{K}^{+}$-ATPase activity in mesonephros. Some osmoregulatory defects were corrected, partially or fully, by transplantation of a single pituitary gland which included anterior and posterior lobes. The principle conclusion drawn from these experiments, however, is that osmoregulatory imbalances in the hypophysectomized embryo cannot necessarily be traced directly to the absence of known avian pituitary osmoregulatory hormones, such as prolactin and AVT. This conclusion is supported by the finding that the metabolic hormones, $\mathrm{T}_{4}$ and corticosterone, were effective in amelioration of some osmoregulatory defects. These hormones, as well as others not considered (such as growth hormone) are deficient in the hypophysectomized chick embryo (Betz, 1975). Accordingly, hypophysectomized embryos show regarded growth, maturation, and reduced metabolism (Betz, 1975). Inasmuch as the normal schedule of mobilization of water and ions in the embryo and the maturation of osmoregulatory organs depends on normal metabolism and development, it may not be easy to detect specific osmoregulatory roles of the pituitary gland during ontogeny using the classical ablation-replacement strategy. This is not to say that an osmoregulatory role does not exist for pituitary hormones in the avian embryo. But against a background of severely compromised metabolism, linking a given pituitary hormone with specific target organs and osmoregulatory responses, will require compensation for metabolic defects which occur in parallel and which have osmoregulatory consequences. The following paper (Doneen and Smith, 1982) uses two alternative experimental strategies and shows that pituitary prolactin and AVT do play osmoregulatory roles in the avian embryo. 


\section{ACKNOWLEDGMENTS}

The authors thank Dr. S. Brown, Dr. P. S. Brown, and $K$. Stocker for a critical reading of this manuscript. Supported by Rackham Faculty Grant and by National Science Foundation Grant PCM 7922985.

Note added in proof. A recent paper [Murphy, M.J., Brown, S. C., and Brown, P. S. (1982). Hydromineral balance in the chick embryo: Effects of hypophysectomy. J. Exp. Zool. 220, 321-330.] also reported effects of hypophysectomy in the chick embryo. Their paper was concerned with the 12-day-old embryo, and a few results differed somewhat from those reported herein for the 16.5-day-old embryo. Most notably, hypophysectomy produced elevated allantoic fluid volume, in contrast to the reduction observed in the older embryos. Such differences emphasize the timedependence of pituitary function during ontogeny (cf. Doneen and Smith, 1982).

\section{REFERENCES}

Ar, A., and Rahn, H. R. (1980). Water in the avian egg: Overall budget of incubation. Amer. Zool. 20, 373-384.

Berl, T., and Betler, O. S. (1979). Renal effects of prolactin, estrogen and progesterone. In "Hormonal Function and the Kidney" (B. M. Brenner and J. H. Stein, eds.), pp. 194-214. Churchill Livingstone, New York.

Betz, T. W. (1967). The effects of the embryonic pars distalis grafts on the development of hypophysectomized chick embryos. Gen. Comp. Endocrinol. 9, 172-186.

Betz, T. W. (1975). A method for the partial decapitation of chicken embryos; its limitations as a substitute for the adenohypophysectomy-and evaluation of "equivalent" methods in amniotes. Acta Endocrinol. (Suppl.) 198, 3-28.

Doneen, B. A. (1981). Effects of hypophysectomy and corticosterone treatment on hepatic lipid in the chick (Gallus domesticus) embryo. Gen. Comp. Endocrinol. 43, 284-291.

Doneen, B. A., and Smith, T. E. (1980). Pituitary gland is required for osmoregulation in chick embryo. Amer. Zool. 20, abstr. 201.

Doneen, B. A., and Smith, T. E. (1982). Ontogeny of endocrine control of osmoregulation in chick embryo. II. Actions of prolactin, arginine vasopressin and aldosterone. Gen. Comp. Endocrinol. 48, 310-318.

Fugo, N. W. (1940). Effects of hypophysectomy in the chick embryo. J. Exp. Zool. 85, 271-297.

Holmes, W. N., and Pearce, R. B. (1979). Hormones and osmoregulation in vertebrates. In "Mechanisms of Osmoregulation in Vertebrates"' (R. Gilles, ed.), pp. 413-533. Wiley, New York.

Hoyt, D. F. (1979). Osmoregulation by avian embryos:
The allantois functions like a toads' bladder. Physiol. Zool. 52, 354-362.

Kallicharan, R., and Hall, B. R. (1977). The in vitro biosynthesis of steroids from pregnenolone and cholesterol and the effects of bovine ACTH on corticoid production by adrenal glands of embryonic chicks. Gen. Comp. Endocrinol. 33, 364-372.

Lamping, J. A., and Thommes, R. C. (1967). Endocrine control of electrolyte distribution in the chick embryo. II. Allantoic fluid, sodium, and potassium. Amer. Zool. 7, abstr. 51.

LeBel, O. D., Poirer, G., and Beudoin, A. R. (1978). A convenient method for the ATPase assay. Anal. Biochem. 85, 86-89.

Murphy, M. J., Brown, S. C., and Brown, P. S. (1980). Hypophysectomy and ion regulation in the chick embryo. Amer. Zool. 15, abstr. 200.

Perez-Gonzalez de la Manna, M., Proverbio, F., and Whittembury, G. (1980). ATPases and salt transport in the kidney tubule. Curr. Top. Membr. Transp. 13, 315-335.

Peterson, G. L. A. (1978). Simplified method for analysis of inorganic phosphate in the presence of interfering substances. Anal. Biochem. 84, 164-172.

Post, R. L., and Sen, A. K. (1967). Sodium and potassium-stimulated ATPase. In "Methods in Enzymology"' (R. W. Estabrook and M. E. Pullman, eds.), Vol. 10, pp. 762-768. Academic Press, New York.

Romanoff, A. L. (1960). "The Avian Embryo." MacMillan, New York.

Sinkiss, K. (1980). Water and ion fluxes inside the egg. Amer. Zool. 20, 385-393.

Steel, R. G. D., and Torrie, J. H. (1980). "Principles and Procedures of Statistics. A Biometrical Approach,"' 2nd ed., pp. 137-194. McGraw-Hill, New York.

Thommes, R. C., and Hylka, V. W. (1977). Plasma iodothyronines in the embryonic and immediate post-hatch chick. Gen. Comp. Endocrinol. 32, $417-422$.

Thommes, R. C., and Lamping, J. A. (1966). Endocrine control of electrolyte distribution in the chick embryo. I. Blood sodium and potassium. Amer. Zool. 6, abstr. 403.

Thommes, R. C., Griesbach, D. A., Hylka, V. W., and Tonetta, S. A. (1979). Hypothalamo-adenohypophyseal-thyroid inter-relationships in the chick embryo. III. Effects of cold stress on plasma total thyroxine $\left(\mathrm{T}_{4}\right)$ levels. Amer. Zool. 19, abstr. 214.

Wise, P., and Frye, B. E. (1973). Functional development of the hypothalamo-hypophyseal-adrenal cortex axis in the chicken embryo (Gallus domesticus). J. Exp. Zool. 185, 277-291. 